\title{
"A ESCRITURA A ESCREVIVÊNCIA A INVENÇÃO A POEMA": PERFORMANCES E DECOLONIALIDADES NAS GRAMÁTICAS CULTURAIS DAS COLETIVAS DE POETAS PERIFÉRICAS
}

\author{
"WRITING. EXPERIENCE. INVENTION. POEM": PERFORMANCE AND \\ DECOLONIALITY IN CULTURAL GRAMMARS WRITTEN BY POETS COLLECTIVES \\ FROM THE OUTSKIRTS
}

\section{Claudiana Nogueira de Alencar}

\begin{abstract}
RESUMO
Este artigo é resultante de uma proposta teórico-metodológica de pesquisa participante e interventiva nos estudos da linguagem, a Pragmática Cultural (ALENCAR, 2014, 2015, 2019), que busca a horizontalidade, a colaboração entre saberes populares e acadêmicos, por meio de metodologias simétricas que valorizem formas de vida e resistência, visando à transformação social. Sob essa perspectiva, analiso a constituição de uma gramática cultural de resistência pelas mulheres participantes de três coletivas de poetas da periferia de Fortaleza. $\mathrm{O}$ arcabouço teórico se assentou nas concepções de performatividade de raça e interseccionalidades, a partir do trabalho de Glenda Melo (MELO; MOITA LOPES, 2013, 2014; MELO; PAULA, 2019); gramática cultural e gramática da dor, discutidas nos trabalhos de Veena Das (DAS, 1995, 1999, 2007; DAS et al., 2004) e em minhas pesquisas (ALENCAR, 2014, 2019); e o conceito de escrevivência, de Conceição Evaristo (EVARISTO, 2007, 2008, 2009). As categorias metapragmática, indexicalidade (SILVERSTEIN, 1993, 2003), performance e entextualização (BAUMAN, BRIGGS, 1990) também fazem parte do nosso construto analítico. Com a investigação, percebi que práticas literárias, culturais e políticas dessas poetas constituem uma gramática cultural que anuncia uma sociedade sem dominação, construída pela feminização da resistência.

Palavras-chave: coletivas de poetas; periferia; performance; gramática cultural ${ }_{\text {; }}$ escrevivência.
\end{abstract}

\section{ABSTRACT}

The present article is the result of a theoretical-methodological proposal for a participatory and interventional research in language studies called Cultural Pragmatics (ALENCAR, 2014, 2015, 2019). It aims at establishing horizontality, the collaboration between popular and academic knowledge, through symmetrical methodologies that value different forms of life and resistance, and seek social transformation. From this perspective, I analyze the compilation of a cultural grammar of resistance by women who participate in three poets collectives on the outskirts of the city of Fortaleza (Brazil). The theoretical framework is based on the concepts of performativity of race and intersectionality according to Glenda Melo (MELO; MOITA LOPES, 2013, 2014; MELO; PAULA, 2019); on the cultural grammar and the grammar of pain as discussed in the works of Veena Das (DAS, 1995, 1999, 2007; DAS et al., 2004); on the notion of escrevivência by Conceição Evaristo (EVARISTO, 2007, 2008, 2009), and on my own research (ALENCAR, 2014, 2019). Other parts of our analytical construct are represented by the categories metapragmatics, indexicality (SILVERSTEIN, 1993, 2003), performance and entextualization (BAUMAN, BRIGGS, 1990). Investigating this subject matter I realized that the literary, cultural and political practices of these poets constitute a cultural grammar that announces a society without domination which will be created by the feminization of resistance.

Keywords: poets collectives; outskirts; performance; cultural grammar; escrevivência.

\section{INTRODUÇÃO}

A poeta Nina Rizzi, em um trecho do ensaio "A poema, caminho para alcançar a própria voz e tantas outras", diz que "no processo de descoberta y escritura da nossa poema, refletimos, produzimos teoria y descobrimos também quem somos. é empoderador, libertador y amoroso conosco y com nossa história" (RIZZI, 2020). E eu me sinto amorosamente tocada para iniciar essa escrita com esse "quem somos", iniciar esse artigo lhes apresentando o meu lócus de enunciação, de contar um pouco da história da pesquisa que originou esse trabalho'.

Em 2014, um grupo de ativistas, participantes de movimentos sociais, coletivos e professores extensionistas da Universidade Estadual do Ceará (Uece) reuniram-se para pensar em ações coletivas com o intuito de enfrentar uma

\footnotetext{
* Universidade Estadual do Ceará (UECE), Fortaleza, Ceará, Brasil. claudiana.alencar@uece.br Pesquisadora Bolsista de Produtividade em Pesquisa do CNPq.

Orcid: https://orcid.org/0000-0002-2759-2750.

1. Uma versão preliminar deste trabalho foi apresentada em seminário que ministrei na Faculty of Medieval and Modern Languages da Universidade de Oxford, em novembro de 2020, com o título Resistências feminizadas: coletivos de poetas afro-basileiras da periferia de Fortaleza. Agradeço à Capes pela bolsa (edital n ${ }^{\circ}$ 1/2019) do Programa Professor Visitante no Exterior (PVEx) que me permitiu desenvolver pesquisa na Universidade de Oxford sobre a Literatura escrita por mulheres, durante todo o ano de 2020.
} 
realidade alarmante: o extermínio da juventude pobre e negra da periferia. Motivados pelo questionamento de jovens participantes da Caravana da Periferia — movimento social que atuava na Serrinha, bairro de Fortaleza onde se situa o campus principal da Uece — sobre como a universidade precisava assumir um projeto popular de transformação social, aquele grupo gestou o Programa Viva Palavra².

Viva a Palavra é um projeto colaborativo, um programa de pesquisa, ensino e extensão. Constituído por vários projetos - que incluem ações como saraus poéticos, contação de histórias, oficinas de escrita criativa, teatro, música, cenopoesia, criação literária e bibliotecas livres —, é realizado por coletivos e movimentos culturais da periferia em articulação com professores e estudantes da Uece. Atualmente, esse grande coletivo de artistas, ativistas e acadêmicos faz parte do movimento de saraus, slams e rolezinhos do Ceará.

Como filha de agricultores e participante de movimentos populares desde cedo, sou uma das que quebraram a "cerca do latifúndio do saber" ao ingressar na universidade pública. Depois, como professora da Uece, usufruindo desse lugar do privilégio, sempre considerado próprio da branquitude (KILOMBA, 2019), me senti comprometida a me engajar naquele processo. Fui uma das pessoas presentes àquelas reuniões que pautavam a violência contra a população periférica como um problema também da realidade universitária e ali me tornei uma das idealizadoras do Programa Viva a Palavra. Hoje atuo na gestão colaborativa, na coordenação partilhada desse programa que defende a literatura como um direito bumano, como escreveu Candido (2004), e a palavra como um modo de resistência ao extermínio da população pobre e negra em territórios de violência. Dessa resistência faz parte a luta para que toda a população tenha acesso aos bens culturais, tenha direito à educação de qualidade, incluindo aqui o letramento literário.

Por meio do Programa Viva a Palavra, sou pesquisadora-participante dos movimentos culturais e literários da periferia de Fortaleza. Talvez mais participante que pesquisadora, uma participante-pesquisadora. Desse lugar, pude conhecer as mulheres que atuam na cena cultural das periferias da cidade; pude compreender o espaço, o papel, a arte, o ativismo dessas mulheres. Desse lugar, vi nascer os coletivos culturais de mulheres escritoras; nos saraus conheci as poetas da periferia. Por isso, trago essas poetas comigo nessas falas, nessa pesquisa ${ }^{3}$, que nunca será um trabalho individual, mas sempre coletivo.

Com elas, teço nossas teorias a partir da perspectiva do feminismo negro e me inspiro em bell hooks para considerar a escrita de mulheres negras como produtora de conhecimentos (HOOKS, 2015). Quero, pois, considerar a escrita literária de mulheres como inventividade, criação de conceitos e categorias para ler e compreender literatura como forma de vida. Assim, vou me apropriar de alguns conceitos de mulheres escritoras para ler outras escritoras: o conceito de gramática cultural, de Veena Das (DAS et al., 2004); escrevivência, de Conceição Evaristo (EVARISTO, 2007, 2008); feminização da resistência, de Sara Motta (2013a); e as pesquisas sobre performatividade de raça e interseccionalidades de Glenda Melo (MELO; MOITA LOPES, 2013, 2014; MELO; PAULA, 2019), para entender a proposta literária e o projeto político cultural dos coletivos de mulheres da periferia de Fortaleza.

\section{COLETIVAS DE POETAS PERIFÉRICAS: PERFORMANCES DE RAÇA E INTERSECCIONALIDADES}

Os trabalhos da linguista aplicada Glenda Melo têm contribuído para a articulação entre os estudos de linguagem e de raça no Brasil (ver MELO; MOITA LOPES, 2013, 2014; MELO; PAULA, 2019). Tais estudos mostram a importância de se considerar o marcador performativo de raça de modo intersecional com os marcadores de gênero, sexualidade e classe social. As interseccionalidades podem ser vistas como marcadores que performatizam formas de vida contra-hegemônicas, "questionando as identidades como fixas e homogêneas" para "desestabilizar sentidos cristalizados na sociedade também sobre raça" (MELO; MOITA LOPES, 2013, p. 243).

Um dos modos de desestabilizar sentidos cristalizados que podem construir relações sociais de crueldade é considerar como performatizamos nossas identidades através de narrativas. Bauman e Briggs (1990) trazem a contribuição da antropologia linguística para compreender os discursos como performances socialmente situadas. Essas performances permitem narrar e ressignificar a vida social, situando nós mesmos em contextos históricosociais. São narrativas que textualizam contextos, contextualizando e descontextualizando discursos. Nesse sentido,

2. Viva a Palavra: Circuitos de Linguagem, Paz e Resistência da Juventude Negra na Periferia de Fortaleza. Proposta aprovada no Edital PROEXT MEC/SESU 2015.

3. Esta pesquisa foi submetida e aprovada pelo Comitê de Ética em Pesquisa da Universidade Estadual do Ceará, Protocolo 47530621.0.0000.5534, Parecer 4.775.705 de 13/06/2019. 
construímos e contestamos identidades com nossas performances narrativas. A esse respeito, Melo e Moita Lopes (2014) afirmam:

A narrativa como performance é um ato performativo, em que sujeitos sociais podem ser reinventados e modificados; por meio dela, as práticas e normas sociais podem ser transformadas, já que é uma performance discursiva ou um fazer pela linguagem. Os participantes estariam, então, construindo a vida social ao focalizar certas histórias, optar por alguns posicionamentos interacionais e ao interagir com outros na performance (MELO; MOITA LOPES, 2014, p. 549).

Nesta seção, apresento os perfis, da rede social Instagram, de três coletivas de mulheres na periferia de Fortaleza: baRRósas; PRETARAU — Sarau das Pretas; e Elas Poemas — Escritas Periféricas. O intuito é analisar as performances identitárias encenadas por mulheres poetas da periferia da cidade que se reúnem em coletivos culturais, ou melhor, em coletivas, como elas denominam.

E como nasceram essas coletivas? É preciso entender que mesmo espaços que se pretendem emancipatórios, como os saraus periféricos, carregam as contradições que subjazem o sistema produtor de desigualdades. Por estarem situados em uma sociedade capitalista, patriarcal e racista, os eventos na periferia são também atravessados por essas ideologias. Os saraus e slams, por exemplo, ainda são eventos predominantemente masculinos. Percebendo isso, as mulheres poetas da periferia decidiram se organizar em coletivos culturais, como elas próprias narram nos perfis desses grupos nas redes sociais. É o que diz a narrativa da coletiva baRRósas.

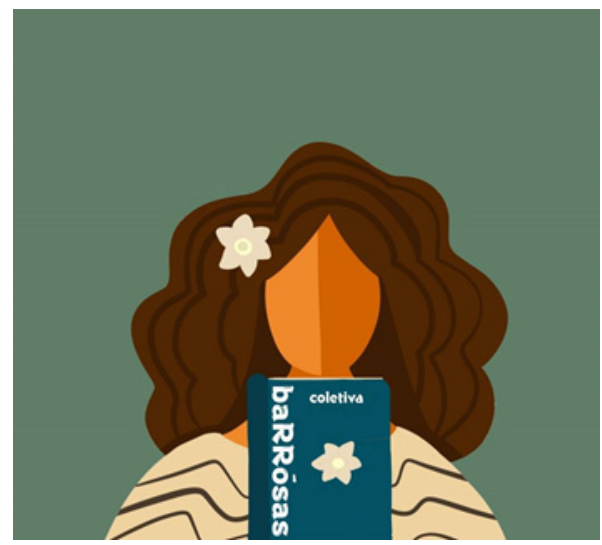

Figura 1. Imagem do perfil baRRósas no Instagram

Fonte: Instagram @barrosaspoesia

BaRRósas, criado por moradoras e moradores do bairro Barroso...

O "gatilho" para essa ideia começou de uma reflexão, após a segunda edição do Slam Violeta, no Conjunto Violeta que fica colado com o bairro Barroso, onde percebemos que dos 15 participantes da batalha apenas 2 (dois) eram LGBT's e os demais todos homens héteros, mas NENHUMA era MULHER.

Com isso veio a inquietação... Por quê? Se nas vivências da nossa Biblioteca (a @bibliotecavivaoficial) são as mulheres que mais leem e escrevem? (...)

Como um espaço para elas e demais mulheres leitoras e escritoras que tantas vezes não se sentem bem participando de eventos culturais tão protagonizados por homens.(...). Mas não estão sozinhas, existem sim diversas mulheres como vocês, como nós, poetas, escritoras maravilhosas que resistem, nesse longo processo de confiança que é sentir-se bem com o outro ouvindo nossos mais escondidos pensamentos. Aqui as manas são as protagonistas, o espaço é nosso, das mulheres!

Vamos juntas!

Ao narrar o episódio que gerou a coletiva, com a constatação de que não havia mulheres participando do slam, as poetas da coletiva baRRósas encenam performances de mulheres escritoras. Desse modo, as sequências de atos de fala que poderiam ser considerados constativos ("apenas 2 (dois) eram LGBT's e os demais todos homens héteros, mas NENHUMA era MULHER"; "São as mulheres que mais leem e escrevem") são atos performativos que buscam reinventar e modificar as práticas artísticas dos saraus e slams como espaços para o protagonismo das mulheres ("Aqui as manas são as protagonistas, o espaço é nosso, das mulheres!"). Podemos perceber que o texto de apresentação da coletiva baRRósas encena performances identitárias de mulheres como "nós, poetas, escritoras maravilhosas que resistem". Nessa narrativa não se percebe outros marcadores performativos, além do gênero e do lugar periférico.

A próxima coletiva, PRETARAU - Sarau das Pretas, narra seu nascimento encenando performances identitárias de raça, gênero e classe social, a partir da performance identitária de pretas periféricas. 


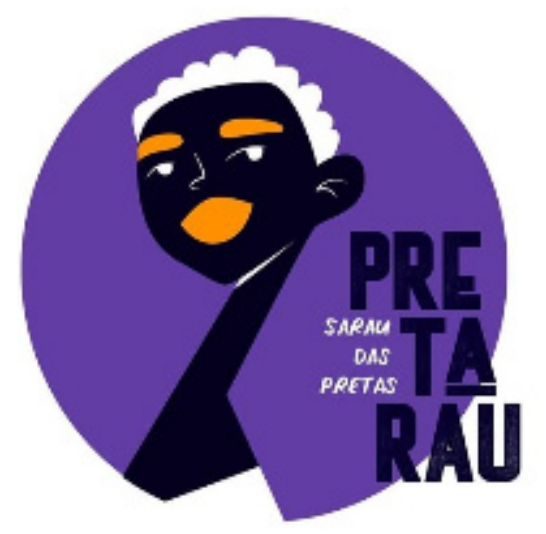

Figura 2. Imagem do perfil PRETARAU — Sarau das Pretas, no Instagram

Fonte: Instagram @pretarau

\begin{abstract}
A Pretarau - Sarau das Pretas é uma iniciativa inédita e independente de mulheres negras poetas e slammers da cidade de Fortaleza e Região Metropolitana, que surge no ano de 2019 por meio da necessidade de um espaço voltado para a celebração de nossos poemas. (...) O Pretarau — Sarau das Pretas tem como principal valor e missão protagonizar mulheres poetas negras, especialmente as pretas que vivem e resistem na periferia. (...) Sabemos que o contexto de surgimento e maior expressão dos saraus, está localizado na periferia e, em decorrência disso, valoriza-se esse espaço como local de potência artística e cultural. Também pela urgência que é construir ações capazes de gerar renda e visibilidade para o movimento de mulheres negras e poetas do Ceará.
\end{abstract}

Quando a coletiva PRETARAU — Sarau das Pretas apresenta sua principal missão "protagonizar mulheres poetas negras, especialmente as pretas que vivem e resistem na periferia", ela remete o texto a uma semântica que para muitos estaria fora dele. No entanto, tal semântica atravessa a própria narrativa, em um movimento de indexicalidade, ou seja, a semântica seria uma pragmática. Para Silverstein (1993, p. 36) a palavra, o signo, indexa, pressupõe ou indicia o seu contexto; o fenômeno da indexicalidade corresponderia à própria pragmática. Desse modo, a frase "protagonizar mulheres negras" traz o implícito de que essas mulheres não têm tido espaço e visibilidade. $\mathrm{Na}$ sequência, a frase "especialmente as mulheres pretas" indexicaliza o contexto cruel de que as mulheres negras retintas sofrem ainda mais as consequências do racismo estrutural do que as mulheres pardas.

A terceira coletiva de mulheres, Elas Poemas - Escritas Periféricas, encena uma performance que marca a identidade de "poetas", articulada pelas marcas performativas de gênero, raça e classe social.

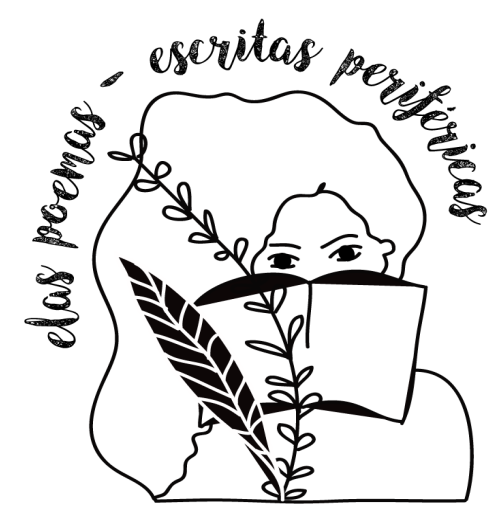

Figura 3. Imagem do perfil Elas Poemas — Escritas Periféricas, no Instagram

Fonte: Instagram @escritasperifericas

\begin{abstract}
Elaspoemas: escritas periféricas é uma coletiva de mulheres que se afirmam como poetas e que se movem para fortalecer a potente arte das palavras das mulheres, por meio dos cuidados e das práticas culturais colaborativas, unindo umas às outras na luta por nosso direito de existência e dignidade. Queremos incentivar as mulheres da periferia a ler e escrever poesia e outros gêneros literários e a colocar a sua arte para o mundo! Também refletir sobre o papel das mulheres nos saraus, na literatura periférica, na cena artística da periferia, discutindo as questões de gênero, de raça e de classe social. (...) Primeiro o estar juntas seria mais para agregar, somar, fortalecer as mulheres em torno da arte da palavra e dar visibilidade a essa arte! E pensarmos em conseguir financiamento, por meio de editais ou práticas de economia solidária para essa coletiva de mulheres se tornar autossustentável. Chega mais perto!
\end{abstract}


Uma performance de cooperação e solidariedade é encenada na autodesignação "coletiva de mulheres que se afirmam como poetas e que se movem para fortalecer a potente arte das palavras das mulheres". A coletiva procura articular "as questões de gênero, de raça e de classe social" como temas a serem discutidos. Essa articulação implica que nas práticas sociais da coletiva Elas Poemas - Escritas Periféricas as identidades são mostradas como desessencializadas. Assim, as interseccionalidades nas performances de gênero, sexualidade, raça e classe social apontam, segundo Glenda Melo, uma preocupação em desnaturalizar sentidos que indicariam desigualdades e sofrimentos. Nessa perspectiva, Melo e Moita Lopes (2013) afirmam:

Entendemos que ser mulher e negra mudaria de acordo com o momento histórico e social em que o sujeito social estaria inserido. Ser mulher e negra estaria relacionado à identificação e à política, dessencializando toda ideia de qualquer pureza racial, pré-existente ao discurso (MELO; MOITA LOPES, 2013, p. 247).

Se por um lado a resistência dessas mulheres em assumir um lugar que sempre lhes foi negado, o lugar de escritoras de suas próprias narrativas, é feminizada (MOTTA, 2013a), por outro, a articulação entre marcas performativas interseccionais, na constituição de performances identitárias, situa o projeto literário dessas mulheres como um projeto político mais amplo, para além das questões de gênero: um projeto decolonial.

\section{GRAMÁTICA CULTURAL: AS PALAVRAS-SEMENTES DE MULHERES POETAS PERIFÉRICAS}

A Pragmática Cultural procura estudar as práticas de linguagem como modos de agir e conhecer, com o intuito de realizar pesquisas que promovam ação-reflexão-ação. A partir da ideia de que estudar a linguagem é voltarse para as formas de vida (WITTGENSTEIN, 1989), a Pragmática Cultural busca alianças entre pesquisadores e participantes de coletivos e movimentos sociais, para o desenho de uma proposta de pesquisa que não apenas realize a descrição das formas de vida, mas que também promova intervenções, por meio da horizontalidade e da simetria entre participantes, que possibilitem a construção e a transformação social no enfrentamento às formas de violência e crueldade, resultantes do sistema capitalista colonial, patriarcal e racista (ALENCAR, 2019).

Assim, sob a perspectiva da Pragmática cultural, foi construído um coletivo de pesquisa, ensino e extensão, o Coletivo Viva a Palavra, que tem estabelecido alianças com as coletivas de poetas periféricas de Fortaleza. Em 2020, o Viva a Palavra participou de uma roda de conversa e de saraus organizados pelas coletivas BaRRósas e Pretarau e, em 2021, tem recebido a Pretarau e a Elas Poemas em seus saraus ${ }^{4}$. Além disso, promoveu um encontro com as poetas das três coletivas intitulado "Mulheres Negras poetizando as re-existências" ${ }^{\prime \prime}$. A partir desses vários encontros, como participante do Coletivo de Pesquisa Viva a Palavra, tenho refletido sobre a gramática cultural das coletivas de poetas periféricas, com o intuito de fortalecer o projeto literário dessas mulheres.

Preciso dizer que a ideia de gramática cultural é fruto da leitura decolonial que faz Veena Das (1999, 2007; DAS et al., 2004) sobre o trabalho de Wittgenstein (1989). A antropóloga, em seu trabalho etnográfico sobre as relações entre gênero, violência e subjetividade, retoma a ideia wittgensteiniana de que as experiências de dor e sofrimento são mostradas a partir de uma gramática, uma vez que, para Wittgenstein, linguagem é sempre coletiva, só existindo enquanto prática, em forma de atividades comuns, como os jogos de linguagem. Nesse caminho, Veena Das (2007) procura mostrar como o nosso cotidiano, nossas formas de vida familiares, em seus jogos de linguagem ordinários, estão articulados com as produções, estruturas e eventos violentos mais amplos. Ela estuda o modo como as mulheres, vítimas de sofrimentos atrozes, provocados por guerras e conflitos políticos, reinscrevem sua dor e sofrimento em jogos de linguagem ordinários, constituindo uma gramática cultural.

Nesse sentido, gramáticas culturais dizem respeito à construção de cenários, traços e rotas, muitas vezes ocultos, construídos na historicidade de nossas formas de vida, que respondem pela produção de discursos e de subjetividades (ALENCAR, 2014). Vale lembrar que as regras de uma gramática cultural não são pré-determinadas, mas são frutos das ações cotidianas, portanto são sempre fluidas e provisórias.

O título deste artigo, um verso de Nina Rizzi, uma das poetas da Coletiva Pretarau, " a escritura a escrevivência a invenção a poema" (RIZZI, 2020) indica caminhos de construção de uma proposta em Pragmática Cultural que

4. Devido à pandemia da COVID-19, esses encontros foram realizados de modo remoto, por meio das plataformas Google Meet, Instagram e Youtube.

5. Realização do encontro "Mulheres Negras poetizando as (re)existências" em 27 de julho de 2020, transmitido pelo canal do Youtube do Viva a Palavra, em alusão ao Julho das Pretas: https://www.youtube.com/watch?v=RBHDx3bR-5g\&t=524s 
considere a escritura dessas mulheres a partir de sua escrevivência, de suas formas de vida, mas também como invenção, como performance, atos de linguagem que ressignificam suas vidas. Assim, elas constroem a poema, índice de uma gramática cultural que reinscreve a violência do sistema colonial e patriarcal, em novas formas de vida.

Conceição Evaristo $(2020$, p. 30) fala dessa reinscrição da violência, quando nos diz que "escrevivência, em sua concepção inicial, se realiza como um ato de escrita das mulheres negras, como uma ação que pretende borrar, desfazer uma imagem do passado (...)". Evaristo se refere a um passado em que o "corpo-voz de mulheres negras era controlado pela violência do sistema colonial escravocrata. A escrevivência é a reinscrição desse corpo- voz na escrita de mulheres que performatizam sua potência em formas de libertação. A escritura das poetas periféricas é "escrita e existência, é amalgamar vida e arte, Escrevivência" (EVARISTO, 2020, p.31). Por isso, trago nos versos de Nina Rizzi as palavras- sementes que situam a proposta deste artigo em uma perspectiva da Pragmática Cultural. Pelo caminho da palavramundo (FREIRE,1982), seguindo as pistas das palavras-sementes de Nina Rizzi (2020), articulo o conceito de performance como reinscrição, a partir de uma gramática cultural que ressignifica a dor, em atos de escrevivência: a poema é a linguagem que cura.

Como nos saraus, olho e sinto o movimento dos círculos. Ao analisar a literatura das poetas periféricas, utilizo os círculos de cultura de inspiração freireana como procedimento metodológico da Pragmática Cultural (ALENCAR, 2015), não apenas para gerar dados na pesquisa-intervenção, mas também para traçar um mapa, como modo de análise em três percursos, seguidos neste trabalho: 1 . escolha das palavras-semente, as palavras-mundo que se transformam em temas geradores; análise dos temas geradores mapeados nas formas de vida, indicadas pelas palavras-sementes; 3 . discussão dos temas geradores em determinada forma de vida para compreender as gramáticas culturais.

Desse modo, colhidas as palavras geradoras, as palavras-sementes dos versos das poetas, em rodas de conversas, saraus e encontros em que discutimos a poema ${ }^{6}$, seguirei a trilha dessas palavras para análise dos temas geradores, nas próximas seções.

\section{A ESCRITURA}

Como parte da gramática cultural de coletivas culturais de mulheres poetas da periferia de Fortaleza, chama a atenção a maneira como a escritura, palavra-semente que traz o tema da escrita literária dessas poetas, mobiliza a enunciação das mulheres sobre a agência da própria escrita, sobre o poder das palavras e a força que tem o seu uso, seja para instaurar relações de opressão, seja para perturbar essas opressões, provocando emancipações.

Podemos reconhecer nessa escritura uma metapragmática, uma vez que reflete sobre o uso das palavras. Conforme Pinto (2019), a metapragmática é um recurso fundamental para direcionar o movimento de um ato de fala em "contextos" específicos. Para a autora, "metapragmáticas são racionalizações sobre o uso da linguagem, inseridas em sistemas locais de interação, e relacionadas às formas metalinguísticas que permitem referenciar e predicar a própria linguagem" (PINTO, 2019, p. 227).

No caso das poetas da periferia, as vozes poéticas enunciadas procuram subverter o sexismo na língua, e o fazem de modo interseccional trazendo as questões de raça e classe social em articulação com as pautas de gênero e sexualidade.

As linguistas feministas já chamavam atenção para o modo como as línguas representam o gênero, reforçando as desigualdades sexuais, tendo no uso genérico de pronomes masculinos seu exemplo mais gritante (CAMERON, 1995; CALDAS-COULTHARD, 2007). As poetas dos coletivos culturais estudados procuram alterar essa prática linguística sexista não apenas na busca de pronomes neutros para um uso mais igualitário, mas modificando a morfossintaxe das palavras, ao transformar sintagmas considerados masculinos em língua portuguesa, tais como "o coletivo cultural" e "o poema", em sintagmas femininos. Daí teremos o uso dos sintagmas "a coletiva" e "a poema". Vejamos a poema de Nina Rizzi:

6. Agradeço especialmente ao convite de Nina Rizzi para a mediação de sua participação no Festival Literário Carnavárias pelo perfil @ carnavalhame da plataforma Instagram, no dia 25 de maio de 2020, quando tivemos uma longa conversa sobre a poema, mesmo quando Nina ainda não havia publicado o seu Ensaio sobre a Poema, aqui referenciado neste texto (RIZZI, 2020). Aquele encontro e, posteriormente, o envio do ensaio por Nina, me permitindo uma leitura antes da sua publicação, foram inspiradores para a produção deste artigo. 
pela cruz pela espada pela doença

e pela linguagem se deu a dominação

a língua castra

a língua de um pai de um estuprador de uma igreja de

[uma polícia de um estado de um

genocida

de um passado que é presente e é fascista racista

[misógino homofóbico vidafóbico e é

colonial

não se encaixar em partículas totalizadoras

masculinais do poder branco

soltar os punhos

a língua a linguagem

chamar a ela: ela

e a quem quiser: querer

A poema é um dialeto originário é um pretuguês é uma

[gíria

(RIZZI, 2020).

Essa ação sobre a língua faz parte do projeto político das poetas de usar a sua poesia para decolonizar os corpos e as vidas marcadas e performadas pela linguagem, como enuncia a voz poética em Nina Rizzi: "A poema é um dialeto original é um pretuguês é uma gíria".

Na poema acima, a menção ao "dialeto original pretuguês" entextualiza o pensamento de Lélia Gonzalez, professora universitária, feminista negra, antropóloga e intelectual brasileira que trouxe a grande contribuição de mostrar que o português brasileiro é fruto da diáspora africana. Gonzalez (1988) reivindica que negras e negros que vieram vítimas de escravização para o Brasil construíram comunidades culturais e constituíram o que chamamos de português brasileiro, que deveria ser chamado de português afro-brasileiro.

[...] aquilo que chamo de 'pretuguês' e que nada mais é do que marca de africanização do português falado no Brasil [...] O caráter tonal e rítmico das línguas africanas trazidas para o Novo Mundo, além da ausência de certas consoantes (como o l ou o r, por exemplo), apontam para um aspecto pouco explorado da influência negra na formação histórico-cultural do continente como um todo (e isto sem falar nos dialetos 'crioulos' do Caribe) (GONZALEZ, 1988, p. 70)

A antropóloga também afirma que o Brasil nada mais é do que uma América Africana, ou seja, uma Améfrica Ladina. Os textos de Lélia Gonzalez representam um legado importante ao movimento negro feminista e se tornaram uma das principais referências nos estudos de raça, gênero e classe no Brasil.

Podemos perceber o pretuguês nas poemas das coletivas, fazendo-se tanto na escolha lexical das poemas, com forte presença de palavras e expressões do cotidiano, inclusive com o uso recorrente de gírias, bem como na entonação conferida às performances das poemas que, apesar de não apresentarem rimas, trazem um ritmo próprio da linguagem oral.

Vale lembrar o cuidado para não se estereotipar o projeto literário das coletivas da periferia afirmando que a literatura periférica apenas retrata a realidade por meio de uma linguagem pobre e de um português não padrão. Sobre a visão preconceituosa e estigmatizante por parte sociedade branca elitista acerca dos falares populares que seriam marcas do pretuguês, Gonzalez (1984) afirma:

É engraçado como eles gozam a gente quando a gente diz que é Framengo. Chamam a gente de ignorante dizendo que a gente fala errado. E de repente ignoram que a presença desse $\mathrm{r}$ no lugar do 1 nada mais é do que a marca lingüística de um idioma africano, no qual o 1 inexiste. Afinal quem é o ignorante? Ao mesmo tempo acham o maior barato a fala dita brasileira que corta os erres dos infinitivos verbais, que condensa você em cê, o está em tá e por aí afora. Não sacam que tão falando pretuguês (GONZALEZ, 1984, p. 238).

Ressalto que, como mostram os estudos sociolinguísticos, o estigma que recebem algumas variantes linguísticas é também motivado por uma visão preconceituosa contra seus falantes (BAGNO, 2001). Como as favelas e a periferia têm sido representadas negativamente na sociedade, moradores/as desses locais sofrem preconceitos, de modo que as variantes linguísticas produzidas por esses/as falantes sejam estigmatizadas. Com a contribuição de Lélia Gonzalez, podemos entender que o preconceito sociolinguístico é igualmente uma manifestação do racismo. 
Um outro aspecto da escritura das poetas periféricas é a menção à corporalidade dessa produção poética. As poetas encenam uma poema encarnada. A poesia tem carne, tem sangue, tem suor, tem vida. O dizer sobre essa poesia encarnada expressa uma metapragmática, um dizer sobre o uso da linguagem como reinscrição da vida com a pujança de suas dores. Um dizer-fazer sobre língua, sobre a poema, conduzindo-nos a uma metaliteratura ou metapoética. Essa metapragmática também performatiza as poetas em sua potência de vida, transformando suas dores em alegria e prazer, como uma terapia pelo uso sempre social da linguagem, como podemos ler na poema de Mika Andrade:

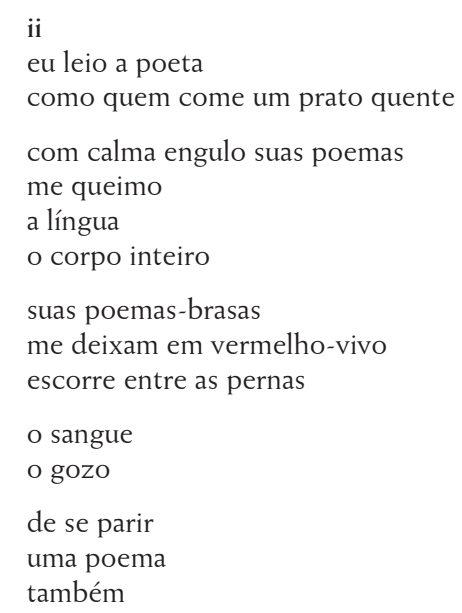

(ANDRADE, 2020a).

Essa metapragmática traz sempre a poesia encarnada, mostrando que o ato de fala é um ato do corpo (PINTO, 2018). Os versos "me queimo/ a língua/ o corpo inteiro" nos fazem sentir essa corporalidade da linguagem, mostrando que poematizar é além das palavras um ato de corpo. O corpo feminino é performatizado também na escrita, o corpo com seus fluidos, o corpo erotizado que sempre foi um signo do incômodo, atravessa o projeto poético dessas mulheres: "escorre entre as pernas// o sangue/ o gozo". Vale lembrar que as poemas das coletivas não são escritas somente para serem lidas, mas para serem declamadas, vivenciadas com o corpo inteiro ${ }^{7}$.

\section{A INVENÇÃO}

Com relação à prática literária de produção, a palavra-semente invenção nos conduz a outro tema gerador na gramática das coletivas de poetas periféricas: a inventividade, a invenção poética. Nos versos "eu leio a poeta/ como quem come um prato quente// com calma engulo suas poemas/ [...] escorre entre as pernas// o sangue/ o gozo// de se parir/ uma poema/ também", tanto na leitura como na escuta das performances em que o texto é declamado, uma poeta é estimulada a criar poemas a partir da poema de outra poeta. Nessas coletivas, há sempre uma preocupação com a escrita das demais participantes. As poetas dizem que não pretendem escrever sozinhas, alcançar apenas o sucesso de uma carreira individual. O mote é "queremos que você venha junta". O "Vamos juntas!", que está na descrição da coletiva baRRósas em seu perfil do Instagram, enuncia essa perspectiva colaborativa de produção poética. Como dizem as palavras de Tony Morrison, citadas por Rizzi (2020):

Conta a tua história! Para nos ajudar a ficarmos mais fortes. Conta sobre o mundo que é só teu. Desenvolve uma história. A narrativa é radical, cria a nós próprias no momento exato em que está sendo criada. (...) Mas tenta. Por nós, e por você mesma (MORRISON apud RIZZI, 2020).

7. Considerar a performance das poetas periféricas é considerar tanto as "estruturas reguladoras pelas quais sujeitos corporificados atingem inteligibilidade cultural (BORBA, 2014, p. 450) ", as estruturas de regulação que sustentam a performatividade (BUTLER, 1993), quanto a materialidade das corpas dessas mulheres que se movimentam e gesticulam com liberdade e força nos formatos circulares dos saraus. $\mathrm{O}$ corpo, que é significado pela regulação da performatividade, também reinventa a dor, a violência e as subjetividades em reinscrições da vida, a partir das gramáticas culturais de resistência contra os silenciamentos impostos pelo sistema capitalista colonial e patriarcal. Desse modo, quando trato de performance, não me refiro ao desempenho físico-corporal próprio de uma encenação teatral, mas ao modo como os corpos, em atos de linguagem, são significados e ressignificam a vida, construindo cenários cotidianos de superação da dor e da violência. Observe corpos e cenários em performances poéticas no Sarau da B1 com a presença da Coletiva Pretarau, no link: https://www.youtube. $\mathrm{com} /$ watch? $\mathrm{v}=8 \mathrm{HoQafB} 9 \mathrm{qZ} 4$ 
Nesse sentido, a invenção é uma afirmação. E a escrita literária é vista como um ato político, como enuncia a poema a seguir:

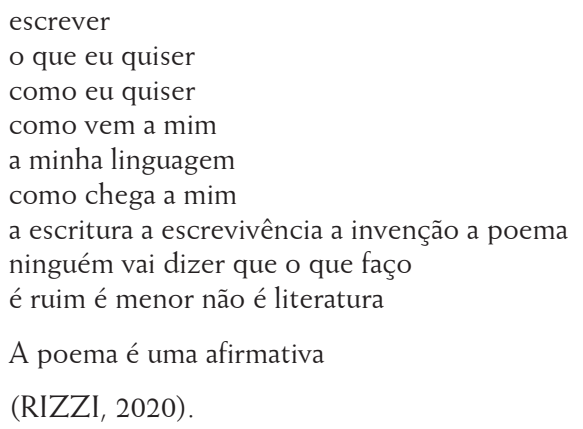

A poema é uma afirmativa

(RIZZI, 2020)

A voz poética enuncia que não há uma escrita feminina com temas "de mulher". Quebrando os estereótipos sobre o feminino, oferece uma contrapalavra ao discurso de que a mulher escreve "temas de mulher", nos versos "escrever/ o que eu quiser/ como eu quiser". A metapragmática, a reflexão sobre o uso dessa escrita presente no verso "ninguém vai dizer que o que faço/ é ruim é menor não é literatura", mostra a consciência política nessa metaliteratura sobre os jogos de poder na constituição do cânone. O cânone é, assim, posto à prova por essas poetas, como na antipoema de Ma Njanu:

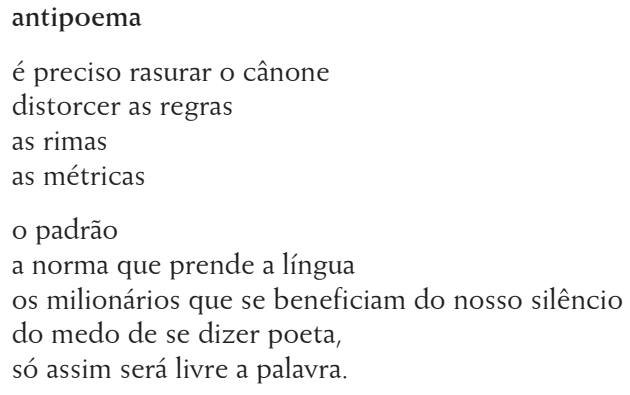

O verso "é preciso rasurar o cânone", de Ma Njanu, indexicaliza o contexto de disputa por poder no campo literário, o que determinaria a constituição do cânone. Segundo Dalcastagnè (2012),

desde os tempos em que era entendida como instrumento de afirmação da identidade nacional até agora, quando diferentes grupos sociais procuram se apropriar de seus recursos, a literatura brasileira é um território contestado (DALCASTAGNÈ, 2012, p. 13).

Para a autora, não se trata de "estilos ou escolhas repertoriais", mas de uma política de representação, a partir da qual "autores e críticos se movimentam na cena literária em busca de espaço — e de poder, o poder de falar com legitimidade ou de legitimar aquele que fala" (DALCASTAGNE, 2012, p. 13).

Desse território em disputa, que é o campo literário, são excluídas as mulheres, as escritoras e escritores afro-diaspóricas/os e pertencentes aos povos originários, as pessoas pobres, faveladas e outros tantos grupos minoritários que não são autorizados a ocupar esse espaço de poder. "Daí os ruídos e o desconforto causados pela presença de novas vozes, vozes "não autorizadas'", como afirma Dalcastagnè (2012, p. 13). Os que se ressentem são representantes de uma elite capitalista neocolonial mascarada de erudição, referidos pela poeta Ma Njanu como "os milionários que se beneficiam do nosso silêncio/ do medo de se dizer poeta". O cânone atuaria nesse apagamento/silenciamento, conforme mostra a poema de Nina Rizzi:

2.

uma máscara branca chamada cânone apaga rasura silencia

— ainda vivas! 
porém não não não

queima queima queima

o trauma colonial

A poema é uma ferida

(RIZZI, 2020).

Com a metáfora "máscara branca" para representar o cânone literário, a poema traz, numa relação intertextual com o famoso título de Frantz Fanon, Pele negra, máscaras brancas, a crítica à violência do colonialismo que dizimou povos e línguas da América e a crítica à colonialidade que continua com suas políticas de embranquecimento a mostrar a ferida desse trauma colonial. O cânone seria constituído a partir dessas relações de colonialidade, uma vez que fornece ainda o lugar preponderante para escritores: homens brancos, hétero e burgueses.

Aqui a poeta também entextualiza a metáfora da máscara que era usada para torturar e silenciar as pessoas escravizadas. A artista negra Grada Kilomba retoma o signo, a máscara, para denunciar os processos de silenciamento das pessoas negras (KILOMBA, 2019). Tal silenciamento atua como modus operandi do racismo na contemporaneidade. O cânone seria uma máscara, pois traria uma ordem de indexicalidade, delimitando quem pode falar, quem pode escrever e quem não pode escrever. Para as mulheres, e mais ainda para as mulheres negras, o cânone sempre funcionou como uma interdição.

\section{A ESCREVIVÊNCIA}

Se podemos falar em escrevivência, quando as poetas cantam a realidade das periferias, essa categoria deve ser entendida não só pelo fato de se tematizar a realidade, as suas vivências em seus escritos. O conceito de escrevivência precisa ser ampliado para além de um modo de escrever/descrever vivências, formas de vida. É preciso recuperálo como um modo de propor, pela escritura das poetas da literatura periférica, novas formas de vida. Temos sim uma escrevivência de denúncia, como a poema a seguir, de Mika Andrade, que tematiza a violência nas favelas e o extermínio do povo preto e pobre.

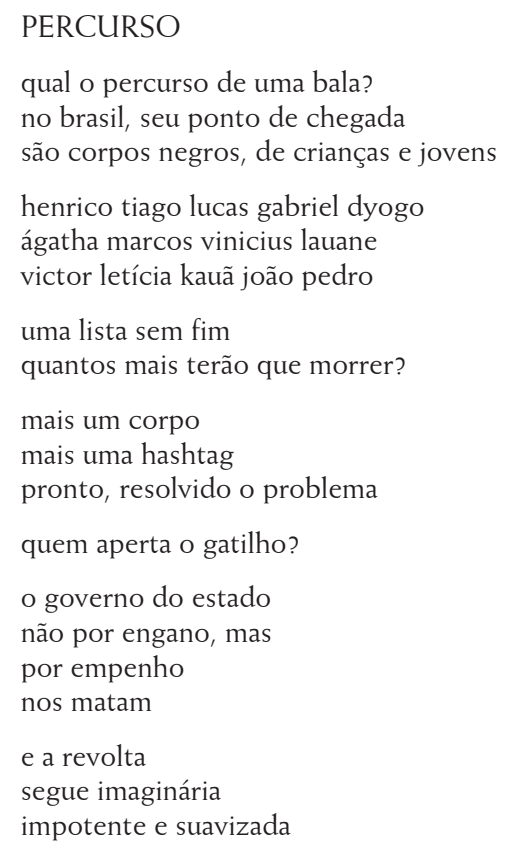

(ANDRADE, 2020b, p. 36)

Silva (2013), em A descoberta do insólito: literatura negra e periférica no Brasil (1960-2000), coloca a literatura periférica como um espaço "onde estão pessoas que agora querem escrever suas vivências, falar de suas experiências, e de uma realidade crua que é seu lugar de enunciação". No entanto, podemos dizer que o projeto literário das poetas das coletivas culturais da periferia de Fortaleza é muito mais do que isso. Em sua gramática cultural, esse projeto literário traz uma performance de denúncia, o que estaria ligado ao que o crítico Haroldo de Campos chama de princípio 
da realidade (CAMPOS, 1997), mas também traz em sua escrita, que performatiza corpos e espaços antirracistas e igualitários em uma escrevivência que anuncia o novo, uma proposição de estética e política diferente, o que corresponderia a um princípio da utopia, conforme Campos (1997). É o que chamarei de escrevivência anunciativa. Podemos perceber esse movimento do princípio da realidade para o princípio de esperança na poema de Ma Njanu:

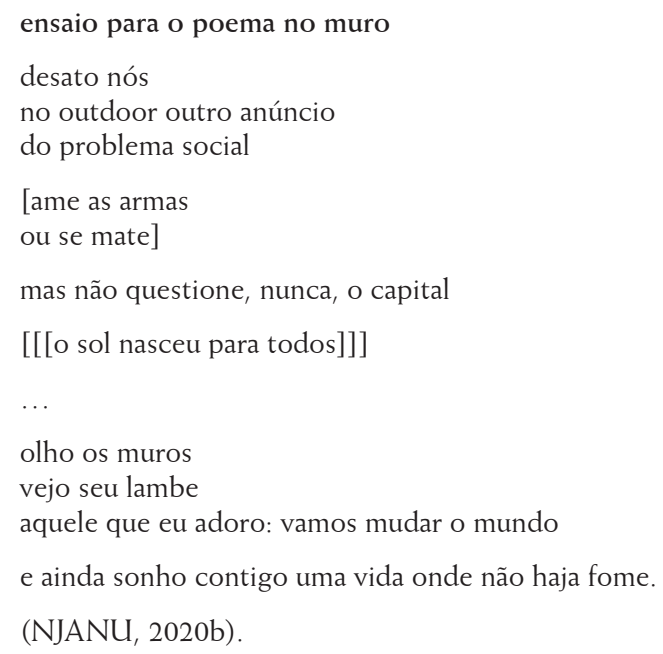

Essa perspectiva de perceber o caráter propositivo e emancipatório da concepção da escrevivência está no seu compromisso com o questionamento das realidades injustas e com a defesa do direito de existir de vozes e modos de vida excluídos pelo sistema-mundo capitalista, racista, colonial e patriarcal. Como nos diz a escritora Conceição Evaristo:

Escrevivência, antes de qualquer domínio, é interrogação. É uma busca por se inserir no mundo com as nossas histórias, com as nossas vidas, que o mundo desconsidera. Escrevivência não está para a abstração do mundo, e sim para a existência, para o mundo-vida (EVARISTO, 2020, p. 35)

Percebe-se, por um lado, a escrevivência da denúncia na ironia "mas não questione nunca o capital" e, por outro, a escrevivência que anuncia uma forma de vida diferente da resultante do sistema mundo capitalista colonial moderno e patriarcal.

\section{A POEMA}

Considerar a escrita literária de mulheres como inventividade, criação de conceitos e categorias para ler e compreender literatura como forma de vida, propósito enunciado por mim no início deste artigo, me trouxe a poema, como palavra-semente enunciada por Nina Rizzi. Palavra-semente que se cultiva como tema, traçado de um mapa, uma das muitas entradas para se alcançar a gramática das poetas das coletivas periféricas. A poema indexicaliza as formas de vida e de arte das poetas da periferia, como nos diz a poeta " e nunca mais parei de dizer y escrever A poema, que também vem sendo dita y escrita por tantas minas, monas y manos aqui nas quebradas" (RIZZI, 2020).

Seguindo as pistas indexicais pelas palavras-sementes de Nina Rizzi (2020), a poema é um pretuguês, uma voz ancestral, uma ferida, uma afirmativa, uma selvagem. Na poema, o marcador performativo de raça, articulado com outras interseccionalidades, performatiza formas de vida contra-hegemônicas pela arte, pela cultura, pela escritura dessas mulheres que constroem suas poemas em novas formas de vida, baseadas na afetuosidade, na solidariedade, na autogestão da coletividade. Se a poema é uma ferida, trazendo a dor da violência colonial, do racismo, ela também é arma. É uma selvagem porque, ao mesmo em que recupera a dor e o sofrimento vivenciado por essas mulheres, por meio da escrevivência, demonstrando o fracasso da gramática do cotidiano para expressar o sofrimento, a poema performatiza essa dor em versos, como se a dor habitasse em outro corpo (DAS, 2007). Esse outro corpo é a poema, um corpo selvagem que subverte o sofrimento, ressignificando-o no plano da realidade e da utopia, na denúnciaanúncio da poesia que explode em muitas outras poemas. Nesse sentido, a poema é cura.

Como uma terapia da linguagem, a poema performatiza o anúncio de uma outra forma de vida, transformando a gramática da dor das mulheres, que por serem mulheres pretas, indígenas, periféricas sofrem os efeitos da violência 
colonial, em uma gramática de resistência. As ações que constituem, não as regras, mas os traçados, as parecenças dessa gramática, desenham uma política da dignidade (MOTTA, 2013b), na feitura de uma gramática de alegria e amorosidade, baseada no cuidado, no fortalecimento em desenvolver atividades colaborativas e horizontais, como as oficinas de escrita criativa e afetiva promovidas por essas mulheres. De minha participação em uma dessas oficinas com Nina Rizzi, colhi as aprendizagens para criar coletivamente a poema e nessa escritura coletiva pude reencontrar a esperança, mesmo em tempos de dor e sofrimento no Brasil ${ }^{8}$. Por essa feitura coletiva, abracei a poema e pude compreender o que nos diz Nina Rizzi: a poema é uma arma, um manifesto:

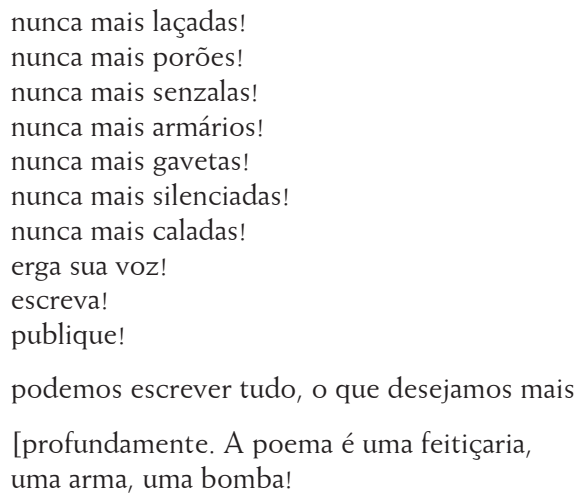

\section{CONSIDERAÇÕES FINAIS}

Através das palavras-sementes e dos temas geradores (escritura, escrevivência, invenção, poema), entextualizados nas poemas das mulheres participantes das coletivas de poetas da periferia, procurei descrever as performances constitutivas de uma gramática cultural tecida nas práticas cotidianas dessas mulheres contra uma sociedade de dominação.

Evidentemente, esse trabalho é apenas uma parte das pesquisas etnográficas e cartográficas que tenho desenvolvido no Programa Viva a Palavra em parceria com as coletivas culturais da periferia, sob a perspectiva da Pragmática Cultural. Pelos conceitos que aqui foram traçados dessa vivência, ouso dizer que as práticas literárias, culturais e políticas das poetas da periferia, participantes das coletivas, constroem uma gramática cultural que aponta para uma nova sociedade, uma sociedade que não seja patriarcal nem matriarcal, mas matríztica. Assim mesmo, com " $z$ ", como escrevem Maturana e Dávila (2016).

A partir da concepção de feminização da resistência trazida por Motta (2013a), que enfatiza a dimensão de gênero nos processos de resistência, posso entender a luta das mulheres na construção de uma sociedade matríztica, como um projeto político em que se instauram as dimensões horizontais do cuidado, da simetria de relações, resultando em políticas de dignidade (MOTTA, 2013a, 2013b). Na gramática cultural das poetas das coletivas, é composta essa feminização da resistência, baseada na autogestão, na autonomia, no respeito mútuo e na construção coletiva, uma sociedade em torno das políticas de dignidade e de esperança.

\section{REFERÊNCIAS}

ALENCAR, C. (2014). Pragmática Cultural: uma visada antropológica sobre os jogos de linguagem. In: SILVA, D.; ALENCAR, C.; FERREIRA, D. (org.). Nova Pragmática: modos de fazer. São Paulo: Cortez. p.78-100.

ALENCAR, C. (2015). Pragmática cultural: uma proposta de pesquisa-intervenção nos estudos críticos da linguagem. In RODRIGUES, M. G. et al. (org.). Discurso: sentidos e ação, Franca, Universidade de Franca, v.10, 2015, p.141-162.

8. No Brasil, o contexto de crise do capitalismo e sua produção de desigualdades e injustiças sociais, aprofundadas pela crise sanitária em decorrência da pandemia de Covid 19, tem provocado o sofrimento, a miséria e a morte da população periférica. Um sofrimento que se tem agravado devido às políticas neoliberais do governo federal que promovem o desmonte das conquistas sociais e trabalhistas, além de cortes nos investimentos em ciência, saúde e educação (ver MAURIEL, 2021). 
ALENCAR, C. (2017). Gramática de resistência do movimento campesino: toponímia, agência e dor. In: ALENCAR, Claudiana; COSTA, Fátima; COSTA, Nelson. (org.). Discursos, Fronteiras e Hibridismos. Fortaleza: Expressão Gráfica Editora, 2017, v. 1, p. $115-136$.

ALENCAR, C. (2019). Tudo aqui é poesia: a pragmática cultural como pesquisa participante com movimentos sociais e coletivos juvenis em territórios de violência urbana. Interdisciplinar, v. 31, p. 237-256, jan./jun.

ANDRADE, M. (2020a). [Eu leio a poeta...]. In: Rizzi, N. Mika Andrade. Escamandro, 17 jun. 2020. Disponível em: https:// escamandro.wordpress.com/2020/06/17/mika-andrade/. Acesso em: 9 nov. 2020.

ANDRADE, M. (2020b). Percurso. In: Rizzi, N.; Andrade, M. (org.). Ofò: antologia poética Pretarau. [S.1.]: Pretarau, p. 36.

BAGNO, M. (2001). Norma linguística e preconceito social. Veredas, Juiz de Fora, v. 5, n. 2, p. 71-83.

BAUMAN, R.; BRIGGS, C. (1990). Poetics and performance as critical perspectives on language and social life. American Review of Anthropology, v. 19, p. 59-88.

BORBA, R. (2014). A linguagem importa? Sobre performance, performatividade e peregrinações conceituais. Cadernos Pagu. n. 43. p. $441-473$.

BUTLER, J. (1993). Bodies that Matter: On the Discursive Limits of "Sex". Nova York, Routledge.

CALDAS-COULTHARD, C. R. (2007). Caro colega: exclusão linguística e invisibilidade. Discurso \& Sociedad, v. 1, n. 2, p. $230-246$.

CAMERON, D. (1995). Verbal bygiene. Routledge: London.

CAMPOS, H. (1997). Poesia e modernidade: da morte do verso à constelação. O poema pós-utópico. In: Campos, H. O arco-íris branco. São Paulo: Imago, p. 243-270.

CANDIDO, A. (2004). O direito à literatura e outros ensaios. Coimbra, PT: Angelus Novus.

DALCASTAGNÈ, R. (2012). Um território contestado: literatura brasileira contemporânea e as novas vozes sociais. Iberic@l: revue d'études ibériques et ibéro-américaines, Paris, n. 2, automne.

DAS, V. (1995). Critical events: an anthropological perspective on contemporary India. New Delhi: Oxford University Press.

DAS, V. (1999). Fronteiras, violência e o trabalho do tempo: alguns temas wittgensteinianos. Revista Brasileira de Ciências Sociais, v. 14, n. 40, p. 31-42.

DAS, V. (2007). Life and words: violence and the descent into the ordinary. Berkeley: University of California Press.

DAS, V. et al. (2004). Violence and subjectivity. Berkeley: University of California Press.

EVARISTO, C. (2007). Da grafia-desenho de minha mãe, um dos lugares de nascimento de minha escrita. In: Alexandre, M. A. (org.). Representações performáticas brasileiras: teorias, práticas e suas interfaces. Belo Horizonte: Mazza, p. 16-21.

EVARISTO, C. (2008). Escrevivências da afro-brasilidade: história e memória. Releitura, Belo Horizonte, Fundação Municipal de Cultura, n. 23, nov.

EVARISTO, C. (2009). Literatura negra: uma poética de nossa afro-brasilidade. Scripta, Belo Horizonte, v. 13, n. 25.

EVARISTO, C. (2020). A escrevivência e seus subtextos. In: Duarte, C.; Nunes, I. (org.). Escrevivência: a escrita de nós: reflexões sobre a obra de Conceição Evaristo. Rio de Janeiro: Mina Comunicação e Arte.

FREIRE, P. (1982). A Importância do Ato de Ler - em três artigos que se completam. São Paulo: Cortez Editora \& Autores Associados.

GONZALEZ, L. (1984). Racismo e sexismo na cultura brasileira. Revista Ciências Sociais Hoje, p. 223-244. 
GONZALEZ, L. (1988). A categoria político-cultural de amefricanidade. Tempo Brasileiro, Rio de Janeiro, n. 92/93, p. 69-82, jan./jun.

HOOKS, B. (2015). Mulheres negras: moldando a teoria feminista. Revista Brasileira de Ciência Política, Brasília, n. 16, p. 193-210, jan./abr.

KILOMBA, G. (2019). Memórias da plantação: episódios de racismo cotidiano. Rio de Janeiro: Cobogó.

MATURANA, H.; DÁVILA, X. (2016). El arbol del vivir. Chile: MVP editores.

MAURIEL, A. P. O. (2021) Crise, pandemia e suas manifestações no Brasil. Direitos, Trabalbo e Política Social, v. 7, p. 41-63.

MELO, G. C. V.; MOITA LOPES, L. P. (2013). As performances discursivo-identitárias de mulheres negras em uma comunidade para negros na Orkut. DELTA, São Paulo, v. 29, n. 2, p. 237-265.

MELO, G. C. V.; MOITA LOPES, L. P. (2014). A performance narrativa de uma blogueira: "Tornando-se preta em um segundo nascimento". Alfa, São Paulo, v. 58, n. 3, p. 541-569.

MELO, G. C. V.; PAULA, L. (2019). Apresentação: Discursos de gênero, sexualidade e raça. Cadernos Discursivos, v. 1, n. 1, p. 1-7.

MOTTA, S. (2013a). "We are the ones we have been waiting for": the feminization of resistance in Venezuela. Latin American Perspectives, v. 40, n. 4, p. 35-54.

MOTTA, S. (2013b). Pedagogies of possibility in, against and beyond the imperial patriarchal subjectivities of higher education. In: Cowden, S.; Singh, G. (ed.). Acts of knowing: critical pedagogy in, against and beyond the university. London: Bloomsbury Academic, p. 85-124.

NJANU, M. (2020a). Antipoema. In: Andrade, M. Como se faz o poema de Ma Njanu. LiteraturaBr, 23 set. 2020. Disponível em: https://www.literaturabr.com/2020/09/23/como-se-faz-o-poema-de-ma-njanu/. Acesso em: 26 set. 2020.

NJANU, M. (2020b). Ensaio para o poema no muro. In: Carbonieri, D. Seis poemas de Ma Njanu. Ruído Manifesto, 18 maio 2020. Disponível em: http://ruidomanifesto.org/seis-poemas-de-ma-njanu/. Acesso em: 30 jul. 2021.

PINTO, J. P. (2018). Corpo como contexto-de-ocorrência de metapragmáticas sobre o português em socializações de estudantes migrantes para o Brasil. Linguagem em (Dis)curso, v. 18, n. 3, p. 751-768, set./dez.

PINTO, J. P. (2019). É só mimimi? Disputas metapragmáticas em espaços públicos online. Interdisciplinar, v. 31, p. 221-236, jan./jun.

RIZZI, N. (2020). A poema, caminho para alcançar a própria voz e tantas outras. Suplemento Pernambuco, nov. 2020. Disponível em: https://www.suplementopernambuco.com.br/edi\%C3\%A7\%C3\%B5es-anteriores/71-ensaio/2579-nina-rizzi-a-poema,caminho-para-alcan\%C3\%A7ar-a-pr\%C3\%B3pria-voz-e-tantas-outras.html. Acesso em: 10 dez. 2020.

SILVA, M. A. M. (2013). A descoberta do insólito: literatura negra e periférica no Brasil (1960-2000). Rio de Janeiro: Aeroplano.

SILVERSTEIN, M. (1993). Metapragmatic discourse and metapragmatic function. In: Lucy, J. (ed.). Reflexive language, reported speech and metapragmatics. Cambridge: Cambridge University Press, p. 33-58.

SILVERSTEIN, M. (2003). Indexical order and the dialectics of sociolinguistic life. Language \& Communication, v. 23, n. 3/4, p. 193-229, July/Oct.

WITTGENSTEIN, L. (1989). Investigações filosóficas. São Paulo: Nova Cultural.

Recebido: 30/7/2021

Aceito: $15 / 10 / 2021$

Publicado: 26/10/2021 